\title{
NUMERICAL OF BIOETHANOL PRODUCTION FROM LIQUID WASTE OF RISE FLOUR BY DISTILLATION PROCESS
}

\author{
Sari Ni Ketut*, I Nyoman Abdi, Wesen Putu, Retno Dewati \\ University of Pembangunan Nasional "Veteran" Jawa Timur, East Java, Indonesia \\ E-Mail: sari_ketut@yahoo.com
}

\begin{abstract}
The availability of liquid waste of rise flour can be maintained in continuously and abundant, and is one of waste water that is underutilized, but liquid waste of rise flour has a starch content which can be used as one of the producers of ethanol. This study has the objective to produce bioethanol and a prototype bio-ethanol industry, and perform simulations before conducting experiments, as well as a reference in developing the bio-ethanol industry in Indonesia.

Based on preliminary analysis obtained starch content of the rice is about $79 \% \mathrm{~b} / \mathrm{b}$, while the starch content of the liquid waste of rise flour is quite high about $30 \% \mathrm{v} / \mathrm{v}$. The process of preliminary research that has been done is the hydrolysis with Bacillus then followed by bacterial fermentation of glucose by Saccharomyces cerevisiae. The quality of ethanol produced is influenced by the levels of starch, glucose, acidity $(\mathrm{pH})$, the volume ratio of waste with Bacillus volume, the number of bacteria Saccharomyces cerevisiae, fermentation time that has been done in the preliminary study. The filtrate resulting from the hydrolysis and fermentation processes of contains ethanol about $16 \% \mathrm{v} / \mathrm{v}$ carried out a batch distillation process to obtain bioethanol, variables in a batch distillation process is ethanol composition and temperature. Before experimental batch distillation process simulation ternary system Ethanol-Water-Impurities (EWI) with a model of Differential-Algebraic-Equations (DAEs), using the programming language Mathlab version 7 in advance, so that in the determination of the variables can be more effective and more research costs cheap.

The results obtained experimentally study the composition of bioethanol a maximum of $95 \%$ to $96 \%$, the results of experiments and simulations EWI ternary system form the temperature profile, the profile of the composition of liquid and vapor composition profile dimensionless time functions both at the bottom and in the distillate shows the results of the same approach. The simulation results before used reference in experiments performed the validation beforehand, so that the ternary system simulation EWI after validation of reference can be used in experiments.
\end{abstract}

Keywords: batch distillation, bioethanol, DAEs, liquid waste of rise flour

\section{INTRODUCTION}

Conventional crops such as corn and sugar cane cannot meet global demand for bio-ethanol production, because their main value on food and animal feed. Therefore, agricultural waste is an attractive feedstock for bioethanol production. Agricultural wastes are costeffective, renewable and abundant. Bioethanol from agricultural waste could be a promising although the process has several challenges and limitations such as biomass transportation and handling. Efficient methods of pretreatment with high in sugar, fermented using enzym, as well as improve the efficiency of the whole process. The conversion of glucose and xylose to ethanol requires new fermentation technology, to make the entire process cost effective (Nibedita, et al., 2012).

The production of bioethanol from sago pith waste (SPW) using microwave hydrothermal accelerated hydrolysis by carbon dioxide. Structural changes in the SPW examined after hydrolysis, the purity of ethanol after fermentation, and distillation. Energy consumption is evaluated for microwave hydrothermal, maximum $43.8 \%$ and $40.5 \%$ glucose theoretical ethanol yield is obtained. Fermentation ethanol yield coefficient was 0.47 ( $g$ ethanol per $g$ glucose) were 15.6 SPW ethanol per $100 \mathrm{~g}$ of dry (Saravana, et al., 2014). Starch is a component that is more complex than a disaccharide, before fermentation, starch must be broken by using amylase in maltose, a disaccharide component. By using enzymes, maltase and maltose is hydrolyzed to glucose (Karimi, et al., 2006).

In the process of separation, thermodynamic data of the most dominant influence on the performance of the process is the equilibrium phase. One of the modern thermodynamics correlation in behavior mempersentasikan mix is not ideal UNIQUAC equation, the approximate equilibrium ternary and quaternary systems can be done only based on experimental data of binary systems. Models UNIQUAC activity coefficient equations developed from a binary mixture, and has the advantage for application in a mixture of multicomponent system because it only requires a binary parameter (does not require additional parameters). But the loss of the model does not always succeed in estimating equilibrium multi-component system that shows a mixture which is not ideal especially for couples with a mix that has limited solubility such as butanolwater. To overcome this necessary equilibrium data measurement accurately binary system and the estimated model parameters of the model so that the activity coefficient of these parameters can be used to estimate the vapor-liquid equilibrium multi-component system accurately (Handogo, et al., 1997).

In the chemical industry, the fermentation process is one way to get chemical compounds with the aid of microorganisms, fermentation products entering the next stage of separation. At this stage it is very important to 
produce a product with a certain purity, one of the tools commonly used in the separation process is a batch distillation column. Separation processes in the industry generally separation of multicomponent and binary separation rare, therefore it is very important to review the multicomponent batch distillation. Design of multicomponent batch distillation is generally obtained by performing a simulation, in order to obtain simulation results closer to the actual state of the thermodynamic accurate data is needed.

\section{Theory of Thermodynamic and Separation}

In the chemical industry, the fermentation process is one way to get chemical compounds with the aid of microorganisms, fermentation products entering the next stage of separation. At this stage it is very important to produce a product with certain purity, one of the tools commonly used in the separation process is a batch distillation column. The separation process in the separation of multicomponent general industry and rarely binary separation, therefore it is very important to review the multicomponent batch distillation. Design of multi-component batch distillation is generally obtained by simulation, in order to obtain simulation results closer to the actual state of the accurate thermodynamic data is needed.

In the separation process, the data thermodynamics of the most dominant influence on the performance of the process is the equilibrium phase. One of the modern thermodynamic correlations in presentation behavior is not ideal mix UNIQUAC equation, the approximate equilibrium ternary and quaternary systems can be done only by the experimental data of binary systems. Activity coefficient models with UNIQUAC equation was developed from a mixture of binary, and has advantages for applications in multi-component mixtures because the system requires only binary parameters (does not require additional parameters). But the loss of the model does not always succeed in estimating equilibrium multi-component system that shows the mix is not ideal especially for couples with a mix that has limited solubility such as butanol-water. To overcome this necessary equilibrium data measurement systems and models of binary accurately estimate the parameters of the model so that the activity coefficient of these parameters can be used to estimate the equilibrium vapor-liquid multicomponent system accurately (Handogo, et al., 1997).

Iterative procedure to find the temperature of the bubble that is looking for a saturation temperature of the pure components temperature saturated (Ti) on pressure (P) (Prausnitz, et al., 2001). T price as the starting price will be used to determine the saturated vapor pressure of a substance to be estimated with the Antoine equation. Activity coefficient $\gamma \mathrm{i}$ obtained from: UNIQUAC equation. Model-Differential-Algebraic Equations (DAES) for batch distillation ternary system, assuming it does not form a two-phase liquid by Doherty and Perkins (1978) as follows:

$$
\mathrm{d} \xi=\frac{-\mathrm{dx}_{\mathrm{i}}}{\left(\mathrm{x}_{\mathrm{i}}-\mathrm{y}_{\mathrm{i}}\right)}
$$

$$
\xi=\ln \left(\frac{\mathrm{W}_{\mathrm{o}}}{\mathrm{W}}\right)
$$

With forward-finite-difference, Equation (2) becomes:

$$
\mathrm{x}_{\mathrm{i}, \mathrm{j}+1}=\mathrm{x}_{\mathrm{i}, \mathrm{j}}+\left(\mathrm{y}_{\mathrm{i}, \mathrm{j}}-\mathrm{x}_{\mathrm{i}, \mathrm{j}}\right) \Delta \xi
$$

The liquid composition initially at bottom (xi, j) and $\Delta \xi$ determined, while the vapor composition $\left(\mathrm{y}_{\mathrm{i}}, \mathrm{j}\right)$ is calculated using Equation bubble-T (Prausnitz, 2001).

\section{METHODOLOGY}

System simulation is studied for EWI ternary system with the composition shown in Table 1 .

Table-1. The feed composition EWI

\begin{tabular}{|c|c|c|c|}
\hline \multicolumn{4}{|c|}{ Feed composition (fraction mole) } \\
\hline Run & Water & Butanol & Impurities \\
\hline 1 & 0,8 & 0,1 & 0,1 \\
\hline 2 & 0,7 & 0,2 & 0,1 \\
\hline 3 & 0,7 & 0,1 & 0,2 \\
\hline 4 & 0,6 & 0,3 & 0,1 \\
\hline 5 & 0,6 & 0,1 & 0,3 \\
\hline 6 & 0,5 & 0,1 & 0,4 \\
\hline 7 & 0,4 & 0,1 & 0,5 \\
\hline
\end{tabular}

To calculate the saturated vapor pressure is used equations Antoine, Antoine parameter data is shown in Table 2. (Prausnitz, 2001), in which the temperature $(\mathrm{T})$ in units of $\mathrm{K}$ and the saturated vapor pressure (PSAT) in units of Bar. To calculate the activity coefficient $(\gamma)$ using equation UNIQUAC, where the price of binary interaction parameters UNIQUAC (uij), molecular volume data (r) and molecular surface area (q) shown in Table 3, assuming the price of $\mathrm{z}=10$.

Table-2. Parameters Antoine EWI

\begin{tabular}{|l|c|c|r|}
\hline & \multicolumn{3}{|c|}{ Parameter Antoine } \\
\hline Component & A & B & \multicolumn{1}{|c|}{ C } \\
\hline Impurities & 4.23 & 4.90 & 5.37 \\
\hline Water & 207.01 & 1475.14 & 1758.22 \\
\hline Ethanol & 228.06 & 182.74 & 230.92 \\
\hline
\end{tabular}

Source: Prausnitz, 2001

Table-3. EWI ternary system parameters UNIQUAC

\begin{tabular}{|l|l|l|}
\hline Component & $\mathrm{r}$ & $\mathrm{q}$ \\
\hline Impurities & 2.3635 & 2.3279 \\
\hline Water & 3.4812 & 3.0533 \\
\hline Ethanol & 2.1054 & 1.9720 \\
\hline \multicolumn{2}{|c|}{ Source: Prausnitz, 2001 }
\end{tabular}

Feed composition shown in Table 1 to calculate the saturated vapor pressure is used equations Antoine, 
Antoine parameter data is shown in Table 2 (Prausnitz, 2001), in which the temperature (T) in units of $K$ and the saturated vapor pressure $\left(\mathrm{P}^{\mathrm{SAT}}\right)$ in units of Bar.

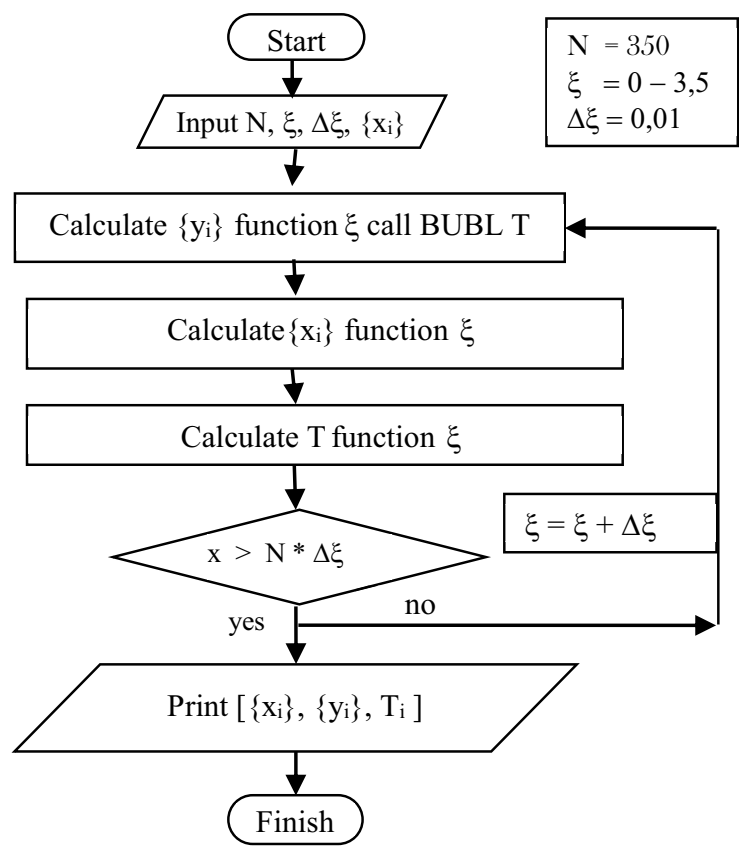

Figure-1. Algorithm batch distillation

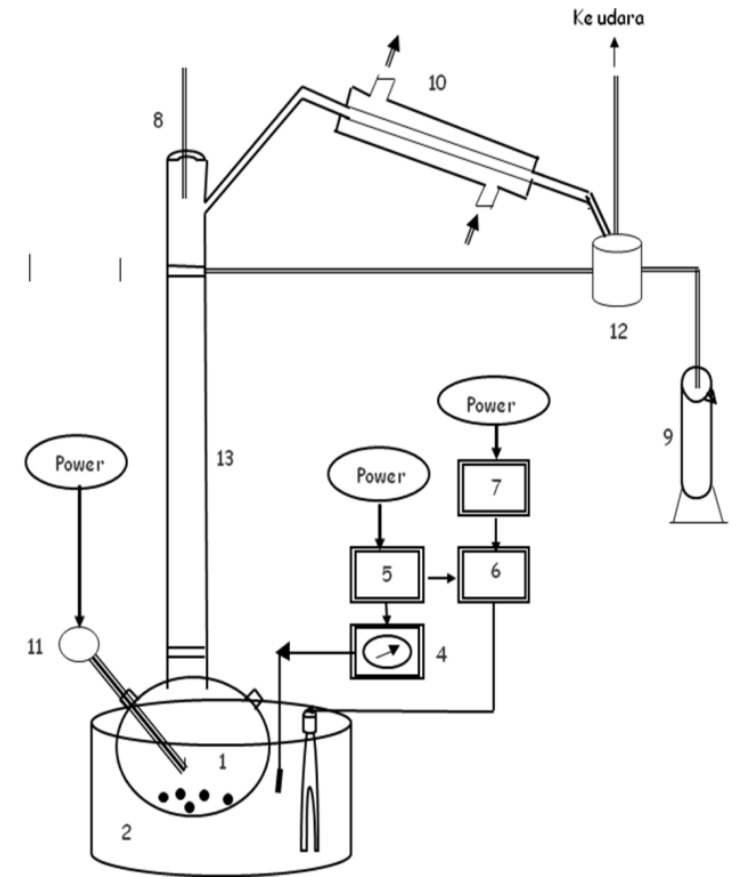

Figure-2. A set of simple batch distillation apparatus

Caption:
1. Still Pot
8. Thermometer
2. Oil batch
9. Measuring cup
3. Heater
10. Condensor
4. Thermocouple
11. Thermocouple RTD
5. Controller
12. Separator column
6. Contactor
13. Packed column

Experimental procedures EWI ternary system using a simple batch distillation, as follows:

a. The simple batch distillation equipment used as in Figure 2.

b. EWI determined volume of $3500 \mathrm{ml}$ mixture with EWI feed composition (mole fraction) are shown in Table 1 .

c. The simple batch distillation process is operated in a state of total reflux.

d. Once the temperature at the bottom with temperatures approaching the same distillate, taken a few drops of volume in the bottom of each $\xi=0$, $1,2,3$

e. EWI Then distillate composition analyzed using Gas Chromatography

f. Once the volume in the still-pot approximately $10 \%$, then a simple batch distillation process is stopped.

\section{RESULT AND DISCUSSION}

Temperature profile at the bottom shows the results closer to the temperature in the distillate, because the batch distillation process is simple to operate in conditions of total reflux. Therefore, the temperature profile simulation results as shown in Figure 3.

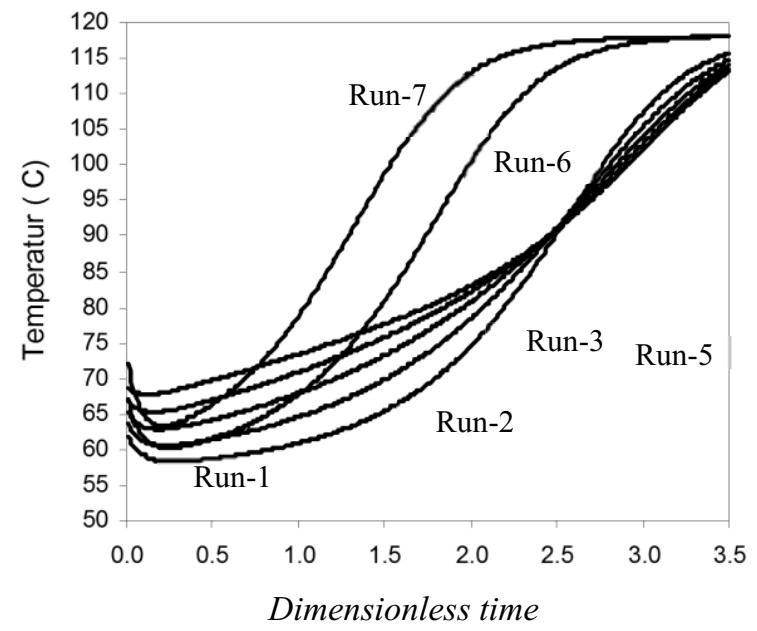

Figure-3. The temperature profile EWI ternary system for Run-1 to Run-7

From Figure 3 shows the temperature profile EWI for Run 1 to Run-7 as a whole rose against the dimensionless time. This is because the components that evaporated with the larger portion components of ethanol, so it takes a greater temperature to vaporize the components butanol which has not evaporated. 


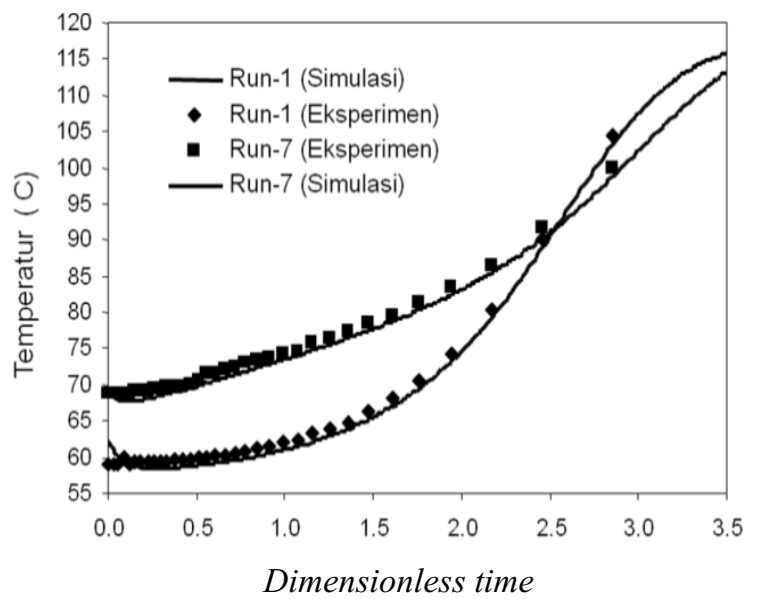

Figure-4. The temperature profile EWI ternary system for Run-1, Run-7 simulation and experimental results

Figure 4 is divided into three areas: one region of activity coefficient for butanol showed declining profile and activity coefficient of ethanol rises so does not affect the temperature profile. Figure 4 shows that the greater the composition of butanol in the feed entering the maximum ethanol influence the activity coefficient when the dimensionless time showed 1.75; after declining in the end a constant profile. The bigger the bait composition of butanol at entry showed a steeper slope of decline in temperature, because the composition of butanol in the feed mixture entering EWI greatly affect the temperature, the greater the composition of butanol in the feed mixture entering the higher temperatures.

For two region temperature profile rose for all the run, the greater the ethanol composition of the feed entry indicates temperature rise slope more gentle. This is because the composition of the ethanol in the incoming feed EWI greatly affect the temperature of the mixture, the greater the ethanol composition of the feed mixture entering the smaller temperature.

For three regions rising temperature profile and most constant, for the temperature rise profile means the separation of a mixture of ethanol EWI still has not evaporated, while for the constant composition profile means it's all the ethanol evaporated. The greater the composition of butanol in the feed mixture entering the temperature the greater and faster the temperature profile constant.

For regions 3.5 dimensionless time temperature profile is not constant, so it takes a dimensionless time greater to obtain a constant temperature profile. If a simple batch distillation continued until the dimensionless time is very large, it will obtain the value of the composition of each mixture negative. Because the ethanol component is volatile components while the components butanol is non-volatile components, when a simple batch distillation process ethanol component in a larger portion is evaporated and the remaining components of butanol. Butanol component has not been approached purely with dimensionless time 3.5 way to obtain a more pure butanol component of the initial composition is to enlarge the composition of butanol in the feed entry.

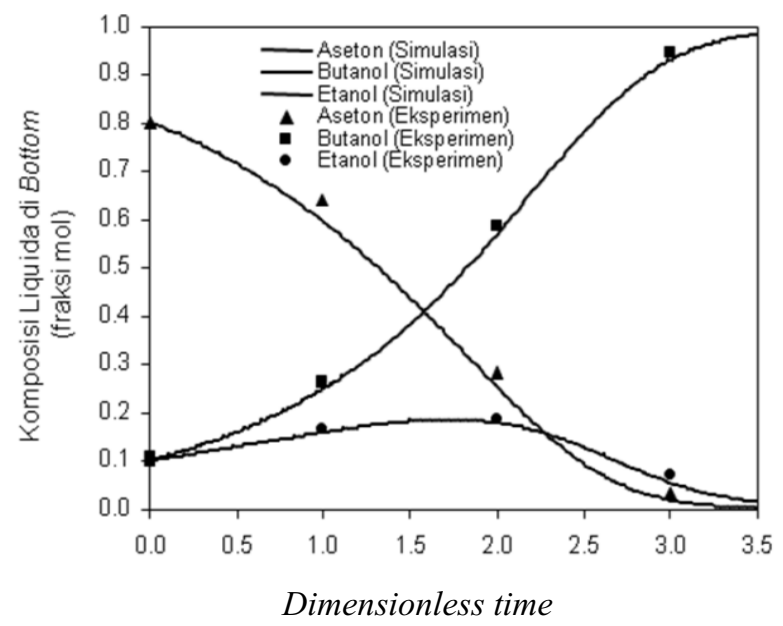

Figure 5. Profile composition of liquid in the bottom ternary systems ABE-1 Run simulation and experimental results.

The composition of the liquid in the bottom profiles and temperature profiles EWI ternary system simulation and experimental basis, to Run -1 indicates that approaching the same profile. For binary systems research has been conducted by Sari, et al. (2007), wherein the composition of the liquid in the bottom profile and temperature profile of a binary system in simulations and experiments showed a similar approach, with an $\begin{array}{lll}\text { average deviation of } & 0.0063 \text {. }\end{array}$

\section{CONCLUSIONS}

$\mathrm{ABE}$ temperature profile as a whole rose to dimensionless time, except at the beginning of the process shows the temperature profile decreases, due to the nature of the characteristics of the mixture.

The composition of the liquid in the bottom profile and temperature profile between the simulation results with experiments show that profiles the same approach, with an average deviation 0.0063

\section{ACKNOWLEDGEMENT}

The authors would like to acknowledge the financial support of the Ministry of National Education of the Republic of Indonesia with the National Strategic Competitive Grant, Contract Number: 180/SP2H/PL/DIT.LITABMAS/V/2013. 


\section{REFERENCES}

Doherty and Perkins. 1978. Model DifferentialAlgebraic-Equations (DAEs), John Wiley \& Sons, Inc., New York.

Handogo, R. and G. Wibawa. 1997. Experiments and Correlations of Vapor-Liquid Equilibria of Acetone-1Butanol-Ethanol Ternary Mixture, International Conference on Fluid and Thermal Energy Conversion. (pp. 587-592). Yogyakarta, Indonesia.

Henley, E. J., J. D. Seader. 1998. Separation Process Principles (pp. 586-712). John Wiley \& Sons, Inc., New York.

Karimi, K. Kheradmandinia S., Taherzadeh MJ. 2006. Conversion of Rise Straw to Sugars by Dilute Acid Hydrolysis. Biomass and Bioenergy, 30, 247-253.

Nibedita Sarkar, Sumanta Kumar Ghosh, Satarupa Bannerjee, Kaustav Aikat. 2006. Bioethanol production from agricultural wastes: An overview, Renewable Energy, 37, 19-27.

Sari N. K., Kuswandi, Nonot S., Renanto Handogo. 2006. Comparation Residu Curve Maps System Ternary ABE with Metanol-Etanol-1-Propanol, Journal: REAKTOR, 13(2), 6-11. Chemical Engineering Department, UNDIP, Semarang, Indonesia.

Sari N. K., Kuswandi, Nonot S., Renanto Handogo. 2007. Separation Binary System Ethanol-Water and Ternary System ABE with Simple Batch Distillation, Jurnal INDUSTRI Jurnal Ilmiah Sains dan Teknologi, 6(5), 28-34. Faculty of Engineering Industrial, ITS Surabaya, East Java, Indonesia.

Saravana Kannan Thangavelu, Abu Saleh Ahmed, Farid Nasir Ani. 2014. Bioethanol production from sago pith waste using microwave hydrothermal hydrolysis accelerated by carbon dioxide. Applied Energy, 128, 277-283.

Prausnitz, J. M. 2001. The Properties of Gases and Liquids, ed. 5, p. A.50-A.51, Mc. Graw-Hill, New York.

Widagdo, S., Warren D. Seider. 1996. Journal Review: Distillation Azeotropic. AIChE Journal, 42(1), 96-130. 